\title{
Borges y El informe de Brodie: Juego de Voces
}

\begin{abstract}
Durante muchos años crei que me seria dado alcanzar una buena página mediante variaciones y novedades; abora, cumplidos los seterta, creo haber encontrado mi voz... La ya wan$z a d a$ edad me bo enseñado la resignación de ser Borges. ${ }^{1}$
\end{abstract}

En el prólogo de El informe de Brodie, Borges dice que ha pasado por un período de contemplación o de reflexión en cuanto a su estilo narrativo, y expresa que el resultado de tal contemplación es esta colección de cuentos. La cita inicial aquí no quiere sugerir que Borges se está refiriendo precisamente al tema de este trabajo, es decir, a un estudio de la utilización técnica de la voz narrativa. Sin embargo, después de leer y analizar los cuentos, es evidente que el empleo de diferentes puntos de vista (las voces narrativas) tiene mucho que ver con el sentido y significado de ellos. Aunque con esta colección de cuentos Borges ha querido crear cuentos directos (p. 17), hay una interesante relación entre la voz que introduce el cuento y la que lo elabora: la mayor parte de ellos están redactados de una manera que compromete una acción recíproca entre el Borges-narrador, y la otra creación borgiana, el personaje-narrador.

Esto sugiere que se puede analizar el punto de vista narrativo en varios niveles: uno, el nivel introductorio o conceptual en el cual se establece el ángulo de perspectiva de Borges-narrador y su relación con el personaje-narrador; otro, el nivel elaborativo (de la trama) donde se descubre la relación entre los hechos contados y este personaje-narrador (sea protagonista o testigo). Un tercer nivel posible tendrá que

1 Jorge Luis Borges, El informe de Bradie (Buenos Aires: Emecé, 1970), p. 10. Todas las siguientes citas encontradas en este estudio que se refieren a esta colección de cuentos aparecerán entre paréntesis dentro del texto. 
ver con la relación entre Borges-narrador, el personaje-narrador, y la vinculación de los dos con los datos o hechos del cuento. Se verá que es en estos tres niveles y en sus interrelaciones donde se descubre la ironía de las situaciones.

Se podría señalar en detalle el hecho de que muchos de los puntos de vista narrativos se encuentran en este volumen, desde la confesión más personal hasta el omnisciente evangelio, pero vamos a omitir lo superficial para concentrarnos en un estudio de los varios niveles o planos de la narración. ${ }^{2}$ Primero trataremos la introducción o concep. ción -el nivel conceptual-; segundo, la elaboración o trama -el nivel elaborativo-; y luego, las ideas que los interrelacionan.

En "La intrusa", el cuento que encabeza la colección y que establece el sentido de distancia literaria que se evidencia en todo el volumen, tenemos la historia de dos hermanos que comparten la misma mujer y terminan matándola para evitar la discordia que había crecido entre ellos. En la introducción se presentan dos orígenes o fuentes para el cuento: una (la cual es improbable), es la que Eduardo, uno de los protagonistas, andaba contando en el velorio de su hermano Cristián. Se descubre que es "improbable" cuando nos enteramos después de la naturaleza de los dos hermanos. La segunda fuente (la cierta), es que alguien lo contó a alguien, y que éste lo relató a Santiago Dabove que, por turno, volvió a contarlo a Borges. Esto, dice Borges, no es nada más que una versión de la historia, y años después, nos explica, había llegado a saber de otra versión "algo más prolija" que confirmaba la versión de Dabove, pero con pequeñas variaciones y divergencias. La segunda versión fue referida a Borges en Turdera por un párroco, y éste lo había oído de su predecesor. Así, el resultado es una historia bastante "distante".

¿Con qué propósito tanto rodeo de fuentes? ¿Será simplemente para ubicar las fuentes o para establecer una distancia literaria? (p. 11) Se puede entender que para un cuento de esta índole se necesita una perspectiva omnisciente que encierre la mayor distancia posible, en comparación con la intimidad envuelta de la narración de primera persona.

2 He omitido una discusión técnica de la voz narrativa, considerándola ya tratada por unos críticos muy aptos como: Wayne C. Booth, The Rhetoric of Fiction (Chicago: The University of Chicago Press, 1961). Lubomír Dolezel, "The Typology of the Narrator: Point of View in Fiction," To Honor Roman Jakobson: Essays on the Occasion of bis Seventieth Birthday, 11 October, 1966 (The Hague: Mouton, 1967), vol. I: 541-552. Norman, Friedman, "Point of View in Fiction: The Development of a Critical Concept," PMLA, 70 (1955), 1160-1184. Percy Lubbock, The Craft of Fiction (New York: Peter Smith, 1945). 
Además, es obvio que se exige el punto de vista omnisciente cuando consideramos el silencioso modo de vivir de los dos protagonistas, y la inclusión de algunos datos aún ignorados por los dos hermanos.

Así, Borges-narrador hace el recorrido y presenta un repaso de algunos de los ángulos y puntos de vista posibles con esta narración: el yo-protagonista y testigo de Eduardo, y la tercera persona de los "alguien" y del párroco. Pero al entrat en la elaboración del cuento los rechaza y opta por la voz omnisciente, con "la tentación literaria de acentuar o agregar algún pormenor" (p. 15).

Algunos de los elementos narrativos tratan de evitar lo personal, y adquieren un sentido de lo tradicional o de fuente común - ("dicen", "se dice", "tenían fama"), pero Borges, con la tentación de jugar con la voz omnisciente se aleja de este ángulo tradicional y niega el abarcamiento total que acostumbradamente encierra - ("nada se sabe", "nadie sabrá", "parece que", "¿quién sabe?"). En cierto momento, quizás burlándose de esto, dice que "lo que ignoramos, ayuda a comprender lo unidos que fueron" (p. 17).

Con "La intrusa" comienzan los juegos que, las más de las veces, se evidencian a lo largo de esta colección. El juego de envolverse en la búsqueda de las fuentes establece una distancia literaria, pero no niega su concepto del cuento directo. En otros de estos cuentos, al analizar la interacción de autor, narrador, cronista y personaje, veremos que este juego se presta a un entendimiento de los resultados y propósitos de los cuentos.

En "El indigno", la historia (una confesión) de Fischbein y su re. lación con su héroe Ferrari sigue el modelo arquetípico de la relación entre Judas y Jesús. Borges-natrador está recordando el pasado; la imagen es anacrónica porque las cosas han cambiado. Se acuerda de don Santiago Fischbein y de los diálogos que sostenían. Recuerda un relato que le había contado Fischbein años antes: "a lo mejor", le dice Fischbein, "le sirve para un cuento, que usted, sin duda, surtirá de puñales" (p. 26). Aquí se introduce la ironía: la verdad es que Borges no ha deslizado ningún puñal, y así, nos lleva a creer que el cuento que sigue será más verídico por esta falta de puñales. Antes de cederle la palabra a Fischbein (la cual viene entre comillas en el cuento), Borges da vuelta a este juego y admite que cambiará, "como es de prever, algún pormenor" (p. 26).

Entrando en el nivel elaborativo, Fischbein confiesa (a Borges) que, de niño, buscando un héroe, dio con un tal Francisco Ferrari, un malevo desconocido a Borges: "Esta debe ser la primera vez que lo 
oye nombrar" (p. 27). Aquí se necesita el punto de vista del yo-protagonista para el propósito de esta confesión. Como en la relación entre Judas y Jesús ("para desgracia de los dos"), Fischbein encarna los atributos de Judas, pero a veces en orden inverso: la gente despreciaba a Fischbein (y él se despreciaba también), pero aún antes de su delación; Jesús, para Judas, fue primero una persona y después divino; Ferrari, para Fischbein, fue primero un dios y después un "pobre muchacho, iluso y traicionado" (p. 31).

Ferrari solía confesar a Borges que no le gustaban los credos del sionismo, que hace del judío "un hombre común, atado, como todos los otros, a una sola tradición y un solo país" (p. 25). Cuando Fischbein denuncia a Ferrari se cree un buen argentino, pero se da cuenta de que fue una equivocación y una desgracia porque dice: "Ojalá me maten. Es lo mejor que puede pasarme" (p. 34).

El tercer cuento, "Historia de Rosendo Juárez", tiene que ver con un hombre que se había hecho matón, pero, a pesar de ello, tenía fama de cobarde. Juárez, personaje-confesante, trata de enderezar su reputación por medio de Borges-confesor. Con un juego de interconexiones, Borges-narrador se enlaza con Juárez-personaje. Borges no conocía a Juárez, pero por medio de otro novelista que había tratado "el asunto", un tal Paredes, Borges había llegado a saber de él. Por otro lado, Juárez sabe bien con quien habla, porque le dice (a Borges): "pero usted me es conocido, señor" (p. 39).

Juárez ahora quiere que Borges arregle los hechos y que escriba la verdad; es una tentativa de eliminar la vergüenza que siente: Un rasgo irónico es que Borges ya había tratado "el sucedido", pero por haber recibido su información de Paredes, puede que no sea la verdad porque a Paredes "le gustaba mentir, no para engañar, sino para divertir a la gente" (pp. 39.40). En el momento del encuentro vemos que sigue sintiéndose avergonzado porque Borges recuerda que lo había encontrado en un bar, sentado ante una de las mesitas, y sintió "de un modo inexplicable que hacía mucho tiempo que no se había movido de ahí, ante su copa vacía" (p. 39). Quizás (considera Juárez), después de contarle a Borges "lo que de veras ocurrió aquella noche", esta nueva versión de los hechos no le va a ayudar a quitarle la reputación de cobarde tampoco, porque reflexiona al final (quizás falsamente): "Qué podía importarme lo que pensaran" (p. 48).

Ahora analizaremos dos cuentos que ejemplifican mejor la habilidad técnica de Borges de jugar con las voces narrativas.

En "El encuentro" Borges-narrador de la introducción es también 
el narrador-testigo de la elaboración, pero es un testigo "distante" y casi fantasmal. El asunto del duelo entre dos hombres ocurrió en 1910 cuando Borges tenía solamente nueve o diez años. Su relación con el cuento y con los personajes era casi imperceptible, y su conocimiento de los hechos es, en gran parte, nada más que percepción o senti. miento también: "Senti la importancia de aquel rito" ( $p .51)$. "Sentí las antiguas cosas elementales" (p. 52), "Yo sentía... el miedo de lo demasiado tarde" (p. 53), "Sentí que un remolino... nos arrastraba y nos perdía" (p. 56). Estuvo allí el Borges-testigo, pero como un observador misterioso e impercibido: Nadie reparó en él (p. 52), es. tuvo en su "soledad de chico entre mayores", y se escurrió sin que nadie lo notara (p. 53). Ahora, siguiendo con su juego con la verdad de los hechos, Borges nos presenta el cuento. Aunque fue un testigo de los sucesos, no está seguro de ellos: "aquí va la historia con las inevitables variaciones que traen el tiempo y la buena o mala literatura" (p. 51); "creo recordar", pero "no sé", no sé "si el abuso del cinematógrafo me sugiere esa falsa memoria" (p. 55); "no entendí ni traté de entender" (p. 53).

Así, en "El encuentro" Borges-narrador nos refiere el cuento de Borges-testiga, y al contemplar el acontecimiento, cumple con lo que había deseado años antes, de niño: "yo anhelaba que alguien matara para poder contarlo después y para recordarlo" (p. 56). En esta ficción, Borges concibe, elabora y contempla la historia; es autor, narrador y testigo.

"Juan Muraña" es un cuento que juega con la autocrítica. Aqul, como en la mayoría de estos cuentos, Borges transfiere el hilo de la narración a otro, en este caso, a Emilio Trápani (viejo compañero de escuela de Borges). Nuestro interés inmediato está en el hecho de que Borges y Trápani nunca se tuvieron afecto. Ahora Trápani critica la falta de conocimiento de primera mano en las composiciones de Borges: "... hablás todo el tiempo de malevos; decime, Borges, vos, qué podés saber de malevos?" (p. 66). Borges, tratando de defender la verdad de sus composiciones, dice que se había documentado, aunque en é: primer párrafo admite que no tenía un verdadero e íntimo conocimiento de tales datos: fue "un meto alarde literario", dice; "el hecho es que me crié del otro lado de una larga verja de lanzas, en una casa con jardín y con la biblioteca de mi padre y de mis abuelos" (p. 65).

3 Para una referencia y compazación de los datos biográficos de Borges véase: Jorge Luis Borges, with Norman "Thomas di Giovanni, "Profiles," The New Yorker, 19 Sept. 1970, pp. 40-ff. 
Aunque parece que no le gusta admitirlo, Borges nos dice que había aprendido los rudimentos del lunfardo de entonces de este Trápani (p. 65). Así se ha creado una situación de contienda entre Borges-narrador y su creación, Trápani-narrador.

La ironía aquí está en el hecho de que Borges, quien siempre ha tenido interés en la tradición argentina (como en esta colección de cuentos), y que se ha jactado de su conocimiento de ella, cree a otro narrador que niega la validez y la veracidad de la habilidad del creador. El resultado es como un juego de autoburla o autocrítica.

Quizás se puede notar otro rasgo irónico en el hecho de que el narrador elaborativo realmente no hable de Juan Muraña (nombre que da título al cuento), sino que presenta una historia de su tía Florentina, esposa de Muraña. El personaje Trápani, quien "conoce a esa gente", no está seguro de los datos; simplemente nos telata lo que había oído. Puede ser que Borges, burlándose de esto, no se sienta tan contrito en transcribirlo para nosotros. Esto, en efecto, sugiere que Trápani no sea un narrador tan fiel a la verdad tampoco, y que su conocimiento de esa gente (como Juan Muraña) quede algo dudoso también.

Los tres cuentos que siguen continúan la exploración de Borges en cuanto a este aspecto de su técnica narrativa. En "La señora mayor" Borges-narrador es otra vez Borges-testigo, pero nos refiere el asunto como el observador imparcial que es "el historiador argentino, que no se deja embaucar", nos dice en un tono burlón (pp. 75-76). Otro juego aparece en "El duelo" donde la situación y los caracteres importan más que los episodios causados (p. 89). La ironía del juego se evidencia, al comenzar, cuando Borges dice que la labor de Henry James le fue revelada por una de sus protagonistas, la señora de Figueroa. Además, aunque Borges-narrador se menciona en la introducción y alude a un conocimiento del personaje, deja de incluir referencias a su relación con la señota de Figueroa en el texto, y sigue tejiendo los hilos desde un punto de vista omnisciente. "El otro duelo" no ofrece tanto en cuanto a nuestro tópico aquí; Borges sencillamente inos relata una historia que le había referido el hijo del novelista Carlos Reyles.

En el cuento "Guayaquil" otra vez es la situación la que importa. Borges-narrador es también Borges-protagonista-San Martín. Se descubre la ironía cuando nos damos cuenta de que Borges cae en la trampa de Zimerman, y que no entiende lo que ha pasado.

Hay, en cierto sentido, un círculo espiral en este cuento. Comienza con una declaración de resignación (en sentido negativo): "No veré", "no iré", "no descifraté" (p. 111). Después, al enterarnos de la posi- 
bilidad de atribuir esta exposición tanto a San Martín como a Borges, podemos compararla con la declaración al final ("no escribiré más", p. 124), la cual nos trae a la memoria lo que se dijo al principio. K2. gresamos, entonces, o al comienzo o a cierto punto cerca del comienzo, pero en un nivel diferente gracias al descubrimiento de lo figural de los personajes. El segundo párrafo ("Releo el párrafo anterior") tiene relación con el penúltimo ("Releo estas desordenadas páginas"), y, además de sugerir lo que nosotros debiéramos quizás hacer (releer), las frases establecen una suerte de modelo circular o espiral para el giro figural que se repite. Si este modelo es evidente, es verdad que la trama subyacente verdaderamente no comenzó con el encuentro de Borges con Zimerman, sino con la entrevista entre Bolívar y San Martín.

Borges-narrador expone claramente los niveles envueltos en las voces narrativas de este cuento: "Confesar un hecho es dejar de ser el actor para ser un testigo, para ser alguien que lo mira y lo narra y que ya no lo ejecutó" (pp. 111-112). Borges-narrador es protagonista (actor), es testigo (de los acontecimientos de Zimerman), y es la figura de otro (de San Martín) que lo ejecutó. La ironía de esto queda dentro del juego de voces o dentro de los ángulos de perspectiva: Borges, figura del ejecutor; Borges, protagonista y actor (que no entiende); y Borges confesante (que no revela nada).

Borges-autor nos ha proporcionado muchas señas que nos llevarán a asociar los dos acontecimientos (la narración de la entrevista entre Zimerman y Borges y la que ocurrió entre Bolívar y San Martín), pero lo importante es que no podemos sacar nada de la entrevista entre Borges y Zimerman con el propósito de tratar de aplicarlo a la entrevista entre Bolivar y San Martín porque no se revela nada - sólo que era una "batalla" entre sus respectivas voluntades, en la que ganó Bolívar (y ahora Zimerman): "el poder estaba en el hombre" (p. 119). Aún las palabras cambiadas no eran importantes, sólo la voluntad de la persona: las palabras "siempre cuentan menos que las personas" (p. 121). Aunque el servilismo estaba en la voz de Zimerman, Borges lo explica así: "nada le costaba darme la razón y adularme, dado que el éxito era suyo" (p. 123). Borges-protagonista firma el renuncio, pero no entiende por qué; Borges-narrador añade aún otra nota de la ironía al final en cuanto a la voluntad de Zimerman, es decir, que aunque la fuerte voluntad de Zimerman se impuso, éste le dice a Borges: "Acato y agradezco su voluntad" (p. 123).

Sea juego de palabras, juego de conceptos, o juego de personajes, la relación y enlazamiento de papeles narrativos aquí sirve de medio para 
subrayar la ironía central - la realización del concepto de la figura, pero una realización que no se cumple.

Antes de terminar, nos quedan dos cuentos para discutir. "El evangelio según Marcos" está trazado, como es de esperar, con la voz omnisciente y casi biblica, porque los hechos narrados tienen relación con los sucesos bíblicos (un diluvio, un arca, un confundir de las lenguas, una dispersión de tribus; curaciones, discipulos, una última cena, y el cordero sacrificado). El cuento es casi pura elaboración omnisciente, sin ni la acostumbrada introducción y traslado de voces narrativas, ni la frecuente contemplación al final. En el último cuento, (el que da título a la colección), el narrador-Borges (narrador conceptivo-traductor y editor), y su amigo Paulino Keins han descubierto un manuscrito del misionero escocés, David Brodie, en un ejemplar de las Mil y Una Noches (vieja fuente favorita de Borges-autor). Ahora, al traducirlo al castellano, Borges-editor nos presentará, imparcial y fielmente, con el informe. Esta es una técnica evidente en los viejos cuentos de Borges, mientras que en los de esta colección, Borges admite que sigue cam. biando algunos pormenores.

Así, las estructuras técnicas de estos cuentos (la utilización de dife. rentes voces en varios planos o niveles), exhiben relaciones inesperadas entre autor, narrador y personaje. Analizando las interrelaciones y conexiones, uno descubre la ironía del juego de Borges: la ironía de establecer una distancia literaria por medio de la fabricación de una serie de narradores o cronistas que, no obstante, enlazan a Borges con el hecho contado; $\mathrm{l}_{\mathrm{a}}$ ironía de crear una contienda entre autor y narrador (como en "Juan Muraña"); la ironía de fingir la presentación de cuentos directos con bases verídicas, y al mismo tiempo, de admitit la inclusión "como es de prever", de ciertos cambios; la ironía de haber aprendido, o de haberse enterado de ciertos datos por medio de sus propias creaciones literarias - sus personajes o cronistas-; y la ironía fundamental de esta colección, la de pretender "la resignación de ser Borges" (p. 10), cuando, en efecto, se revela estar representando muchos papeles diferentes dentro de los cuentos. Cuando Borges dice en su prólogo que cree haber encontrado su voz, podemos compartir este sentimiento --sólo añadiendo que su voz es muchas voces-; la resignación de ser Borges es, esencialmente, la de ser muchos.

\section{Arizona State University.}

OWen L. Kellerman 